\title{
Correction to: Effect of Friction Stir Welding of Aluminum Alloys \\ AA6061/AA7075: Temperature \\ Measurement, Microstructure, and Mechanical Properties
}

\author{
Pratik S. Godhani, Vivek V. Patel, Jay J. Vora, Nishit D. Chaudhary
}

and Rishab Banka

\section{Correction to:}

Chapter "Effect Friction Stir Welding of Aluminum

Alloys AA6061/AA7075: Temperature Measurement, Microstructure, and Mechanical Properties" in:

D. Deb et al. (eds.), Innovations in Infrastructure, Advances in Intelligent Systems and Computing 757, https://doi.org/10.1007/978-981-13-1966-2_53

In the original version of the book, the title of Chapter 53 has been changed from "Effect Friction Stir Welding of Aluminum Alloys AA6061/AA7075: Temperature Measurement, Microstructure, and Mechanical Properties" to "Effect of Friction Stir Welding of Aluminum Alloys AA6061/AA7075: Temperature Measurement, Microstructure, and Mechanical Properties". The erratum chapter and the book have been updated with the change.

The updated version of this chapter can be found at https://doi.org/10.1007/978-981-13-1966-2_53 